\title{
COMPARATIVE STUDY OF PRIMARY STABILITY BETWEEN IMMEDIATE PLACED IMPLANTS AND DELAYED IMMEDIATE PLACED IMPLANTS IN MANDIBULAR SINGLE ROOTED TEETH
}

\author{
Mohab M. Magdy ${ }^{1} B D S$, Sherif S. Mohamed ${ }^{2} B D S, M S c, P h D$,
} Hala R. Ragab ${ }^{3} B D S, M S c, P h D$

\begin{abstract} stability of immediate and delayed immediate placed implants. implants using resonance frequency analysis device in mandibular single rooted teeth. teeth had undergone implant placement two weeks after tooth extraction (Delayed immediate implant placement). (student t-test) of 0.792 and the p- value of the study was 0.458 which is statistically insignificant. placed implants.

KEYWORDS: Primary stability, Immediate placed implants, Delayed immediate placed implants.

1. Bachelor of Dentistry,Faculty of Dentistry, Alexandria University, Alexandria, Egypt.

2. Professor of Oral and Maxillofacial Surgery, Faculty of Dentistry, Alexandria University, Alexandria, Egypt.

3. Assistant Professor of Oral and Maxillofacial Surgery, Faculty of Dentistry, Alexandria University, Alexandria, Egypt.
\end{abstract}

INTRODUCTION: The timing of implant placement after tooth extraction has been a matter of discussion in dental implant treatment. Primary stability of the implant placed can be measured by the resonance frequency analysis (RFA) which is used to compare the primary

OBJECTIVES: This study was designed to compare between primary stability of immediate placed implants and delayed immediate placed

MATERIALS AND METHODS: Ten patients were selected from Department of Oral and Maxillofacial Surgery, Faculty of Dentistry, Alexandria University divided into two groups, Group A: Five patients indicated for extraction of single rooted teeth had undergone implant placement immediately after tooth extraction (Immediate implant placement). Group B: Five patients indicated for extraction of single rooted

RESULTS: For group A patients the average mean and standard deviation of the primary stability of the placed implants was $61.75 \pm 8.21$ ISQ units while for group B patients the average mean and standard deviation of the primary stability of the placed implants was $67.38 \pm 11.59$ ISQ units. After comparing these results it was shown that the average mean and standard deviation of the primary stability of all cases of group B is greater than the average mean and standard deviation of the primary stability of all cases of group A, which results in a t-value

CONCLUSIONS: There is no significant difference between the primary stability of immediately placed implants and delayed immediate

Corresponding Author:

Mohab Mamdouh Magdy Banoub

e-mail: Mohab.Mamdouh@gmail.com

\section{INTRODUCTION}

Dental implant is a prosthetic device of alloplastic material implanted into the oral tissue beneath the mucosal and periosteal layer within bone to provide retention and support for fixed or removable prosthesis (1). Moreover, dental implants are now a recognized form of tooth replacement as many studies have documented high success rate of osseointegrated titanium dental implants to support both fixed restorations and removable overdentures for partially dentate or completely edentulous patients (2-4).

At the Third ITI (International Team of Implantology) Consensus Conference in 2003, a new classification system for timing of implant placement after tooth extraction was proposed to which a slight modification to it was made in a 2008 ITI publication, this classification system was based on the desired clinical outcome of the wound-healing process, rather than on descriptive terms or rigid time frames following extraction $(5,6)$.

Type I placement (Immediate placement) is the placement of an implant on the same day of the tooth extraction as part of the same surgical procedure. Type II placement (Delayed immediate placement) is the placement of the implant after soft tissue healing before any clinically significant bone fills the socket (typically two to eight weeks of healing). Type III placement (Early delayed placement) is the placement of the implant after significant clinical or radiographic bone fills the socket (typically 12 to 16 weeks of healing) (7).Type IV placement (Late delayed placement) is the placement of the implant in a fully healed site (typically more than six months of healing) (8).

Implant stability is considered one of the most important parameters in implant dentistry. Implant stability can be defined as the absence of clinical mobility, which is also the suggested definition of osseointegration, it affects the healing and successful osseointegration of implants (9).

Implant stability (total stability) is usually divided into two stages: primary stability (implant stability reached during implant placement) and secondary stability (implant stability after healing). Primary implant stability has been proven to be a mechanical phenomenon, while secondary stability is a result of biologic events (osseointegration) (10).

Several methods have been proposed to determine implant stability non-invasively in clinical practice, but only two of them which are measurement of damping capacity by periotest and resonance frequency analysis (RFA) have been considered sufficiently valid $(11,12)$.

Osstell ${ }^{\circledR}$ resonance frequency analysis device is effective for measuring primary implant stability, it is a 
simple, non-invasive diagnostic device that many clinicians currently use, the RFA device provides a useful measurement to assess osseointegration and communicate with other providers and researchers (13-15).

The result of a measurement is presented as a dedicated parameter which is the implant stability quotient (ISQ). The implant stability quotient unit (ISQ) is based on the underlying resonance frequency and ranges from one (lowest stability) to 100 (highest stability). The higher the ISQ value, the more stable the implant. They provide valid indications that the acceptable stability range lies above 55 ISQ (16-18).

So in this research the main hypothesis was to make a comparative study between the primary stability of immediately placed implants and delayed immediate placed implants in mandibular single rooted teeth using resonance frequency analysis device.

\section{MATERIALS AND METHODS}

This study was a randomized clinical trial on ten cases selected from outpatient clinic of the Oral and Maxillofacial Surgery department, Faculty of Dentistry, Alexandria University. An appropriate ethical clearance has been obtained from the faculty and the informed consent had been signed by patients. The ten cases were divided into two groups:

Group A: Five cases indicated for extraction of mandibular single rooted teeth had undergone implant placement immediately after tooth extraction (Immediate implant placement).

Group B: Five cases indicated for extraction of mandibular single rooted teeth had undergone implant placement two weeks after tooth extraction (Delayed immediate implant placement).

The inclusion criteria for this research were age ranging from 20-40 years, sufficient bone volume, good oral hygiene, non- smokers and the presence of a mandibular single rooted tooth indicated for extraction. The exclusion criteria were active infection (periodontitis or mucosal infection), current chemotherapy or radiotherapy, indication for bone graft in the implant site, alcohol or drug abuse, uncontrolled systemic diseases (Diabetic, Autoimmune diseases,....etc).

\section{The implant system}

Ten Neobiotech CM IS II implants (Neobiotech company, Korea) with different diameters (3.5, 4, $4.5 \mathrm{~mm}$ ) and lengths $(10,11.5,13 \mathrm{~mm})$ were used in this study.(Fig.1)

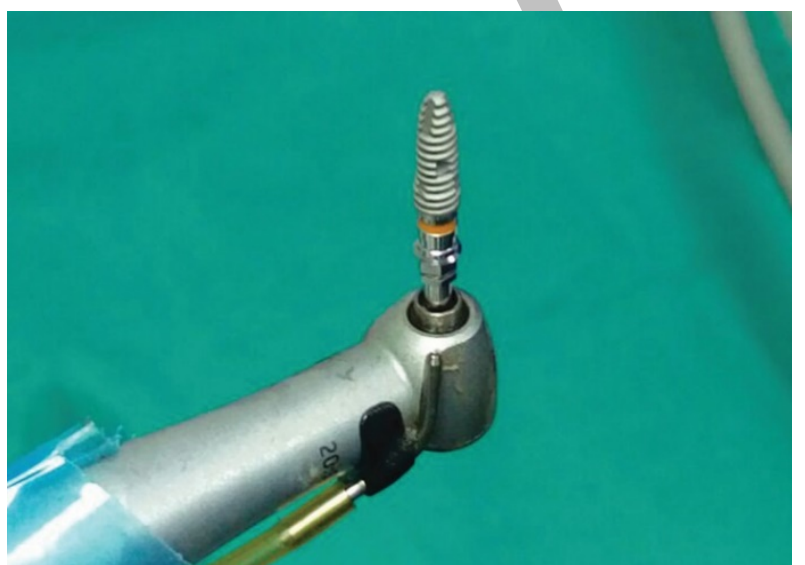

Figure 1: Photograph showing the neobiotech CM IS II implant. Osstell ISQ device
The Osstell ISQ (Gothenburg, Sweden) is the implant stabiliy meter that uses resonance frequency analysis as a method of measurement of the implant stability (primary and secondary stability). (Fig.2)

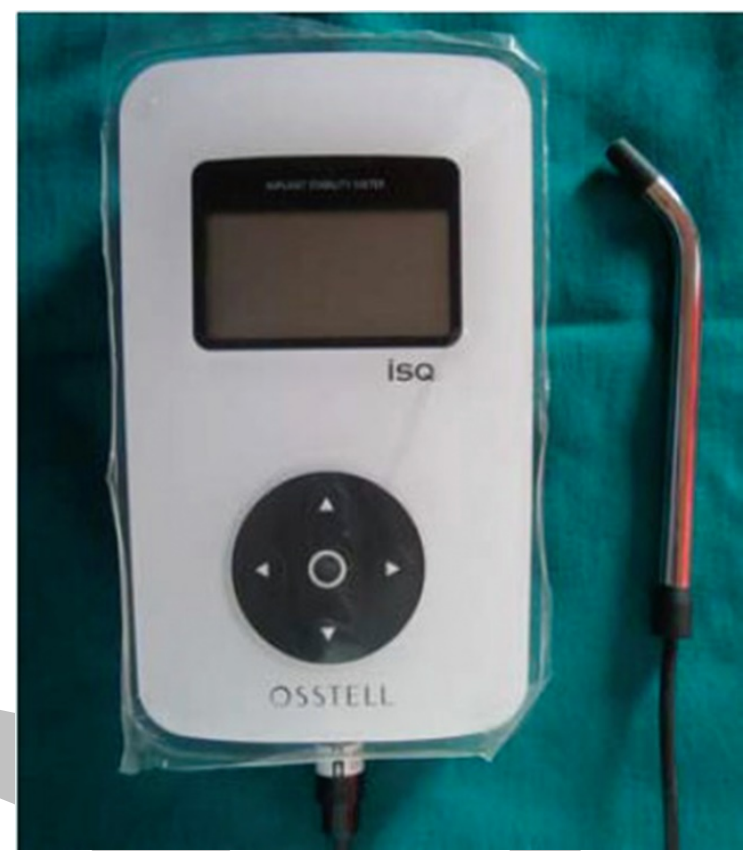

Figure 2: Photograph showing the Osstell ISQ.

\section{Methods:}

\section{A- Preoperative phase}

\section{Clinical examination}

Patient's data were collected; name, gender and age, medical and dental history was taken. Clinical examination was performed where in immediate implant placement cases the tooth to be extracted was clinically examined for mobility, inflammation of the gingival tissue, relation to the surrounding teeth and presence of any abscess while in the delayed immediate implant cases the oral mucosa of the edentulous area was examined for color, texture, firmness and thickness, the edentulous area of the operative site was examined for undercuts by palpation through the soft tissue.

\section{Radiographic examination}

Also all patients underwent pre-operative radiographic examination using Cone beam computed tomography (CBCT) to measure the available bone, selection of the right size implant for optimal support, precision placement of implants in the bone, their relation to adjacent structures and to evaluate the condition of bone. (Fig.3)

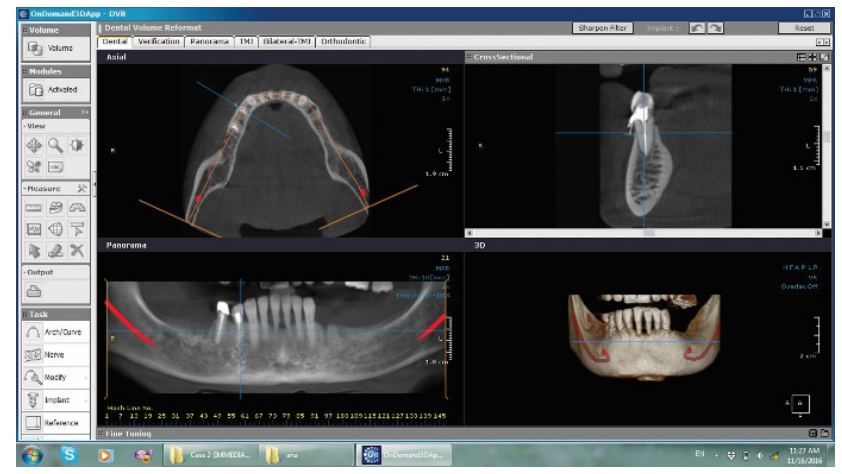

Figure 3:Photograph showing Cone beam CT of the two cases showing mandibular right premolar (Group A, Immediate placement) \& missing mandibular left premolar (Group B, Delayed immediate placement). 


\section{B-Surgical phase}

Preoperative oral antibiotics one hour before surgery was given in the form of Amoxicillin $875 \mathrm{mg} /$ clavulanic acid $125 \mathrm{mg}$ (Augmentin1gm: GSK GlaxoSmitheKline, England) and $0.12 \%$ chlorhexidine (Hexitol: the Arab drug CO, Egypt) mouth wash was used to rinse for 30 seconds before operation.

The surgery began with the patient under local anaesthesia (infiltration anaesthesia) (Articaine HCL with epinephrine 1:100,000) (Ubistesin forte: 3M ESPE, Germany).

For patients in group A (Immediate implants) (Fig .4), the tooth was carefully extracted with the help of periotome (atraumatic technique to save as much of the crestal bone as possible), the socket was debrided with a sharp curette and irrigated thoroughly with normal saline solution to clean it form any periodontal debris and undesirable bone chips. The osteotomy was prepared through the socket opening with copious sterile saline irrigation where the implant bed at the apical portion of the socket was prepared by drilling 2-3mm beyond the apex, a parallel pin was placed in the osteotomy site to confirm the position and the angulation of the osteotomy, the osteotomy was then widened using an intermediate (twist) drill and the final drill according to the diameter of the implant then the implant was threaded into the bone using a ratchet with insertion torque between 30 and50 Ncm.

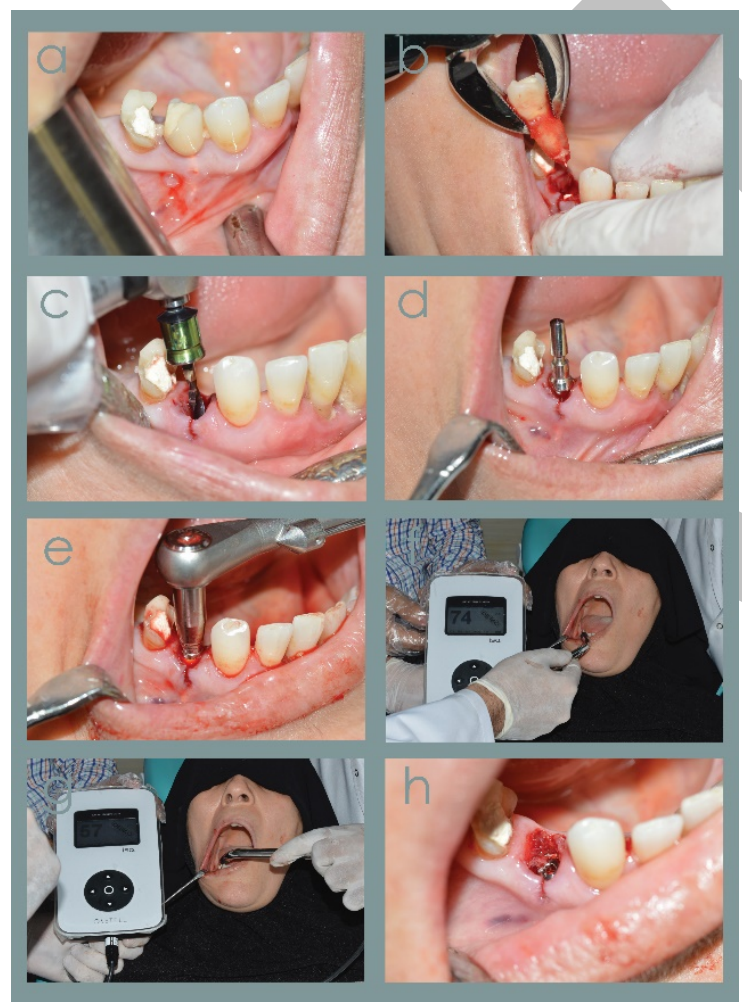

Figure 4:Photograph showing immediate placement technique

a. Photograph showing the tooth

b. Photograph showing tooth extraction

c. Photograph showing initial drilling

d. Photograph showing parallel pin placement

e. Photograph showing implant placement

f. Photograph showing buccolingual measurement of primary stability using Osstell ISQ.

g. Photograph showing mesiodistal measurement of primary stability using Osstell ISQ.

h. Photograph showing the cover screw placement.
For patients in group B (Delayed immediate implants) (Fig. 5), the tooth was carefully extracted with the help of periotome (atraumatic technique to save as much of the crestal bone as possible), a tissue punch was used to remove the gingival tissue exposing the alveolar bone at the site of implant placement, the osteotomy was carried out in the central part of the alveolar bone where the initial drilling of the implant site was done with a pilot drill of $2.2 \mathrm{~mm}$ according to the implant length pre-measured from the CBCT, a parallel pin was placed in the osteotomy site to confirm the position and the angulation of the osteotomy, the osteotomy was then widened using an intermediate drill and the final drill according to the diameter of the implant, the implant was then threaded into the bone using a ratchet with insertion torque between 30 and $50 \mathrm{Ncm}$.

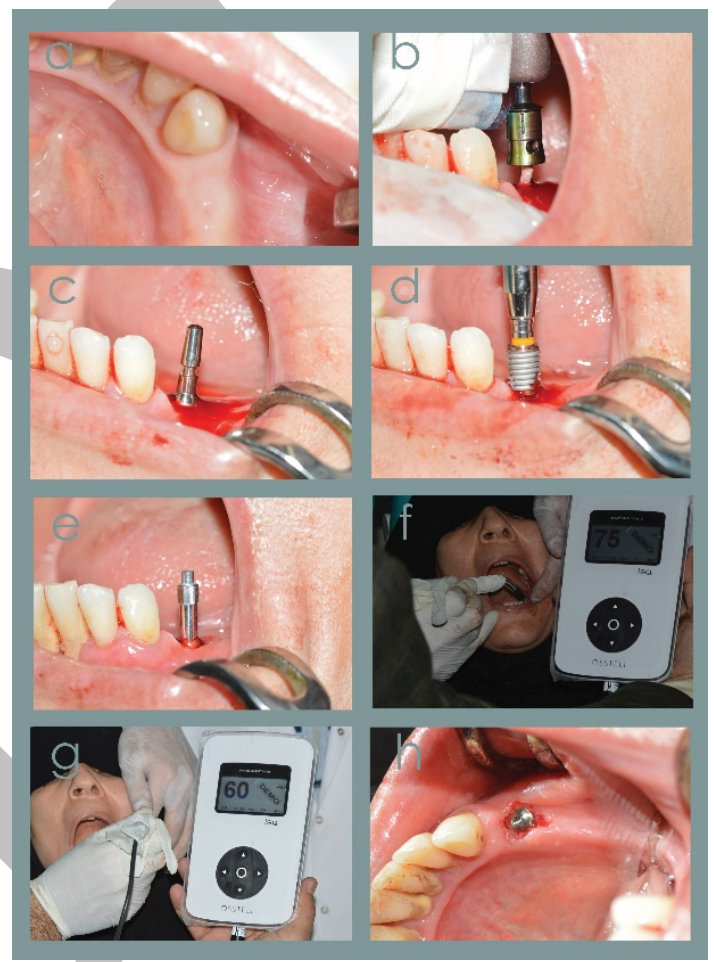

Figure 5: Photograph showing delayed immediate placement technique

a. Photograph showing missing mandibular left premolar.

b. Photograph showing initial drilling.

c. Photograph showing parallel pin placement

d. Photograph showing implant placement

e. Photograph showing smartpeg placement.

f. Photograph showing buccolingual measurement of primary stability using Osstell ISQ.

g. Photograph showing mesiodistal measurement of primary stability using Osstell ISQ.

h. Photograph showing the cover screw placement.

\section{Measurement of the primary stability}

The SmartPeg was connected to the smartpeg mount then it was screwed onto the implant, using approximately 4-6 Ncm of torque.

The measurement probe was held close to the top of the SmartPeg without touching it. When the instrument senses the SmartPeg, the ISQ value was displayed on the screen of the portable instrument.

The cover screw was then placed in place with the screw driver. 


\section{C-Postoperative phase}

\section{- Postoperative instructions}

All patients were advised to apply cold packs extra orally intermittently every ten minutes for two hours on the first day, chlorohexidine mouth (Hexitol: the Arab drug CO. Cairo, A.R) wash was started on the second post-operative day three times daily for two weeks, the sutures were removed after one week post surgically. Antibiotic Amoxicillin (875) / clavulanic acid (125) 1gm tab (Augmentin: GSK GlaxoSmitheKline, England) two times daily for five days, non-steroidal anti-inflammatory drugs ibuprofen 400mg (Ibuprofen: EIPICO, tenth of Ramadan city, Egypt), three times daily for three days were given.

\section{- Postoperative follow-up}

\section{Clinically}

All patients are examined clinically for:

\section{i.Pain}

Pain was evaluated using Visual Analogue Scale (VAS)

(19) on the second and seventh post-operative days. It's a horizontal line, $100 \mathrm{~mm}$ in length, anchored by word descriptors at each end. The patients mark on the line the point that they feel represents their perception of their current state. The VAS score is determined by measuring in millimeters from the left hand end of the line to the point that the patients mark. Tenderness and discomfort were evaluated according to the signs and symptoms of the patients.

\section{ii. Gingival index}

Evaluation of gingival condition around the implant for presence of any inflammation. This was assessed using the Löe and Silness Gingival Index (20) on the 2nd and 7th post-operative days. The category criteria for assessment were as follows:

0 Normal gingival.

1 Mild inflammation, slight change in color, slight edema, no bleeding on probing.

2 Moderate inflammation, redness, edema and glazing, bleeding on probing.

3 Severe inflammation, marked redness and edema, ulcerations, tendency to spontaneous bleeding.

iii. Primary stability

The stability of the implant placed was measured immediately after the implant placement in the mesiodistal and buccolingual directions of the implant and the ISQ value was recorded for the implant primary stability in each direction.

iv. Mobility of the implant

Mobility was tested according to McKinney and Koth (21) (during the post operative follow up phase as only primary stability was measured) using back and forth pressure by two instrument handles. Implant mobility indicates lack of osseointegration. Therefore, mobility was used as a specific diagnostic test pointing to loss of osseointegration and being decisive in making the decision to remove the affected implant.

The clinical implant mobility scale is:

Scale 0: Absence of clinical mobility in any direction.

Scale 1: Slight detectable horizontal movement.

Scale 2: Moderate visible horizontal mobility up to $0.5 \mathrm{~mm}$. Scale 3: Severe horizontal movement greater than $0.5 \mathrm{~mm}$. Scale 4: Visible moderate to severe horizontal movement and any visible vertical movement.

\section{Radigraphically}

All patients were evaluated radigraphically immediately post-operatively and on intervals of three\& six months by periapical $\mathrm{x}$-rays which gave a view of higher resolution and greater accuracy; it was useful in identifying the location of the implant in relation to the bone surface, the relative parallelism of the implant to the adjacent roots of the remaining natural teeth and to ensure the success of the implant with no signs of bone resorption around the implant.

\section{D-Prosthetic phase}

The final prosthesis (porcelain fused to metal crown) was placed after three months.

\section{Statistical analysis}

The statistical analysis was performed to make a comparison between the primary stability of immediately placed implants and delayed immediate placed implants. The used tests were: Paired t-test, ANOVA with repeated measures, Wilcoxon signed ranks test, Chi square for Friedman test.

\section{RESULTS}

The present study was conducted on ten cases requiring single -tooth implant placement (nine patients with two implants placed in one patient) (nine females), selected from the outpatient clinic of the Oral and Maxillofacial Surgery Department, Faculty of Dentistry, Alexandria University. Their ages ranged between 20 and 40 years with mean age of 30 years. All the teeth replaced in this study were single rooted mandibular teeth where Group A cases (immediate placement) were one case with right mandibular first premolar, one case with left mandibular central incisor, one case with right mandibular lateral incisor, one case with left mandibular canine and one case with right mandibular lateral incisor. For Group B cases (delayed immediate placement) were one case with missing left mandibular first, one case with missing left mandibular central incisor, one case with missing left mandibular second premolar, one case with missing left mandibular canine and one case with missing right mandibular first premolar.

Implants used in this research were five implants $(4 \mathrm{~mm}$ diameter \& $13 \mathrm{~mm}$ length implants), three implants (3.5 mm diameter\& $11.5 \mathrm{~mm}$ length implants), one implant (4.5 mm diameter \& 13mm length implant) and one implant (4mm diameter \& $11.5 \mathrm{~mm}$ length implant).

All patients were followed up both clinically and radiographically for six months. Final restorations for all cases were performed after three months from implant placement.

All patients had been examined periodically during the follow-up period up to six months. All patients had completed the scheduled follow up.

Healing was uneventful in all cases with no postoperative complications. Other clinical parameters had been recorded during the follow up period such as: Pain index, gingival index, implant mobility and primary implant stability.

1)Pain

After surgery, all patients experienced slight to mild pain at the surgical site. Eight patients experienced mild pain which subsided on the third postoperative day while two patients experienced slight pain which vanished on the second postoperative day. 


\section{2) Gingival Index}

No signs of gingival inflammation were observed in all patients all over evaluation period. (i.e. gingival index score was zero)

\section{3)Implant mobility}

All over the evaluation period, none of the implants showed any signs of mobility. (i.e. mobility score was zero)

\section{4)Primary implant stability evaluation}

The implant stability measurement was examined at the time of insertion of the implants for the two groups of patients (Group A\& Group B) using the resonance frequency analysis via the Osstell ISQ system, where each implant was measured in two directions mesiodistally and buccolingually and the average value was taken (Table $1 \& 2)$.

Table (1): Distribution of the studied cases according to primary stability of immediate placed implants (Group A) $(\mathrm{n}=5)$

\begin{tabular}{|r|c|c|c|}
\hline & Mesiodistally & Buccolingually & Average \\
\hline Case No. & & & \\
1 & 74 & 57 & 65.5 \\
2 & 51 & 57 & 54 \\
3 & 53 & 59 & 56 \\
4 & 52 & 56 & 54 \\
5 & 73 & & 70 \\
71.5 \\
Min. - Max. & $51.0-74.0$ & $57.0-70.0$ & $54.0-71.50$ \\
Mean \pm SD. & $62.75 \pm 12.45$ & $60.75 \pm 6.24$ & $61.75 \pm 8.21$ \\
Median & 63.0 & 58.0 & 60.75 \\
\hline
\end{tabular}

Table (2): Distribution of the studied cases according to primary stability of delayed immediate placed implants (Group B) $(n=5)$

\begin{tabular}{|r|c|c|c|}
\hline & Mesiodistally & Buccolingually & Average \\
\hline Case No. & & & \\
1 & 75 & 60 & 67.5 \\
2 & 51 & 53 & 52 \\
3 & 80 & 80 & 80 \\
4 & 56 & 60 & 58 \\
5 & 72 & 68 & 70 \\
\hline Min. - Max. & $51.0-80.0$ & $53.0-80.0$ & $52.0-80.0$ \\
Mean \pm SD. & $69.50 \pm 12.77$ & $65.25 \pm 11.59$ & $67.38 \pm 11.59$ \\
Median & 73.50 & 64.0 & 68.75 \\
\hline
\end{tabular}

\section{For group A}

The maximum value of primary stability measured for all the implants of the group in a mesiodistal direction was 74 ISQ units, while in a buccolingual direction was 70 ISQ units and the minimum value of primary stability measured for all implants of the group in a mesiodistal direction was 51 ISQ units while in a buccolingual direction was 56 ISQ units with an average value of all cases of group A, Min. Max $=51.0-74.0$ ISQ units, the average mean and standard deviation for of all cases of group A was 61.75 \pm 8.21 ISQ units and the average median value calculated for these cases were 60.75 ISQ units.

\section{For group B}

The maximum value of primary stability measured for all the implants of the group in a mesiodistal direction was 80 ISQ units while in a buccolingual direction was 80 ISQ units and the minimum value of primary stability measured for all the implants of the group in a mesiodistal direction was 51 ISQ units while in a buccolingual direction was 53 ISQ units with an average value of all cases of group B Min. Max $=53.0-80.0$ ISQ units, the average mean and standard deviation for of all cases of group B was $67.38 \pm 11.59$ ISQ units, where the average median value calculated for these cases were 68.75 ISQ units.

After comparing the above results of the primary stability of the two studied groups it was shown that the average mean and standard deviation of the primary stability of all cases of group B who received delayed immediate implants was greater than the average mean and standard deviation of the primary stability of all cases of group A who received immediate implants which, which results in a t-value (student t-test) of 0.792 and the $\mathrm{p}$ - value of the study was 0.458 which is statistically insignificant as shown in the table. (Table 3, Fig 6)

Table (3): Comparison between the two studied groups according to average of primary stability

\begin{tabular}{|c|c|c|c|c||}
\hline & $\begin{array}{c}\text { Immediately } \\
(\mathbf{n}=5)\end{array}$ & $\begin{array}{c}\text { Delayed } \\
\text { immediately } \\
(\mathbf{n}=5)\end{array}$ & $\mathbf{t}$ & $\mathbf{p}$ \\
\hline $\begin{array}{c}\text { Average of } \\
\text { primary stability }\end{array}$ & & & & \\
Min. - Max. & $54.0-71.50$ & $52.0-80.0$ & & \\
Mean \pm SD. & $61.75 \pm 8.21$ & $67.38 \pm 11.59$ & 0.792 & 0.458 \\
Median & 60.75 & 68.75 & & \\
\hline
\end{tabular}

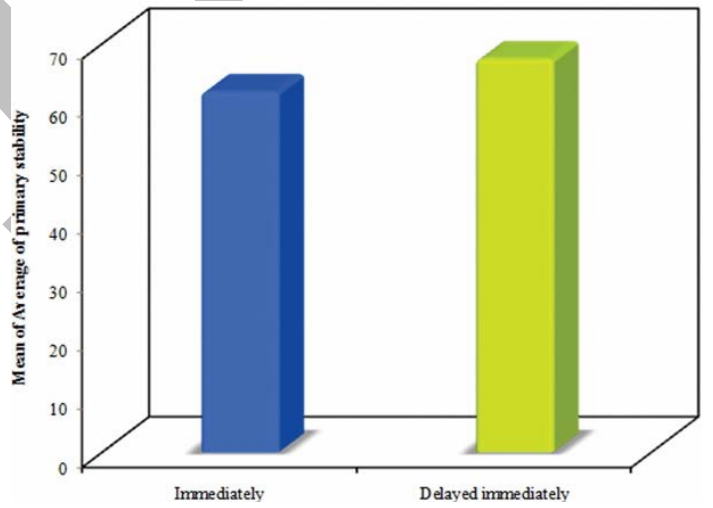

Figure 6: Photograph showingthe comparison between the two studied groups according to average primary stability.

\section{DISCUSSION}

Dental implants are becoming one of the most predictable alternative treatment for many clinical situations, and their long term success over time has been well established (22).

The timing of implant placement after tooth extraction has been a matter of discussion in dental implant treatment. A waiting period of 12 months or longer to allow socket healing has been the "gold standard" protocol (23). Various alternatives to this approach may be considered in order to reduce the treatment/ waiting time.

However, Denissen and Kalk in 1991 (24) demonstrated that the immediate technique is no doubt convenient to the patient and also possesses biological and prosthetic advantages, one advantage is that normal bone healing 
within the extraction alveolus takes effect around the implant this may lead to preservation of alveolar bone height and width and enhance the bone to implant contact.

Therefore, the present study was designed to make a comparative study of primary stability between immediate placed implants and delayed immediate placed implants in mandibular single rooted teeth.

The selected patients were free from any uncontrolled systemic diseases or conditions that may complicate the surgical procedure or the healing process of the implant. This was following a study performed by Bornstein et al in 2009 (25), where they reviewed whether systemic diseases with/without systemic medications increased the risk of implant failure and therefore diminish the success and survival rates of dental implants. They stated that the level of evidence indicative of absolute and relative contraindications for implant therapy due to systemic diseases is low.

Also, patients suffering from bruxism, heavy smokers, patients receiving chemotherapy or radiotherapy and immunosuppressed patients were excluded from this study. This was following a study performed by Gomez de Diego et al in 2014 (26), where they reviewed the current scientific literature in order to analyze the indications and contraindications of dental implants in medically compromised patients and they concluded that tobacco addiction and head and neck radiotherapy are correlated to a higher loss of dental implants.

In the current study strict oral hygiene was followed by all patients during the preoperative and postoperative follow up. A number of reports of dental implants procedures have highlighted the value of maintaining strict oral hygiene measurements and using antibiotics preoperatively. Postoperative drugs including antibiotics, mouthwashes, analgesics and anti-inflammatory were prescribed for all patients. Implant placement procedures run a risk of introducing new bacteria, requiring the use of prophylactic antibiotics to prevent the infection. The antibiotic administration has been demonstrated not only to minimize the incidence of postoperative infection but also to significantly reduce the rate of implant failure (27).

Implant stability was measured using the Resonance frequency analysis (RFA) via the Osstell ISQ system. RFA was chosen as a non-invasive and reliable method to assess variation in implant stability over time. RFA registrations are directly related to the stability of the implant in the surrounding bone: during healing an increase in implant stability quotient (ISQ) values presumably reflect new bone apposition at the implant-bone interface (28-31).

Meredith et al in1996 (12), concluded that RFA is a method that can serve as a useful research technique and it is valuable in studying the behavior of implants in surrounding tissue where resonance frequency analysis is the most objective and reliable method for measuring the stability of an implant during any stage of implant therapy and it has been widely used for clinically assessing osseointegration, as well as for prognostic evaluation.

This is in agreement with Jaramillo et al. in 2014 (32), who reported that resonance frequency analysis systems in Osstell Mentor and Osstell ISQ show almost perfect reproducibility, repeatability and accuracy.

Primary implant stability is mainly attributed to the surgical technique and implant taper, during our study two surgical techniques were used. In the immediate technique the tooth was carefully extracted with the help of periotome and the implants were placed immediately into fresh extraction socket, the diameter of the implant should be equal or slightly more than the socket diameter and implant length is $3-5 \mathrm{~mm}$ beyond the socket depth to increase the primary stability.

In the delayed immediate technique the tooth was carefully extracted with the help of periotome, a tissue punch was used to remove the gingival tissue exposing the alveolar bone at the site of implant placement and the implant were placed two weeks after tooth extraction.

In both techniques a low speed high torque hand piece was used for the preparation of the implant bed, and the drilling was performed under profuse irrigation using cold normal saline for proper cooling and to avoid overheating of the bone tissues which would compromise osseointegration in accordance to Strbac et al in 2014 (33).

Garber et al. (34) proposed that the immediate technique simplifies the classical sophisticated implant placement and saves a lot of time. In addition drilling only 3-4 mm beyond the root apex protects the bone from excessive heat generation, atraumatic extraction preserves the wall of the extraction socket and improves the primary stability.

Moreover, as in this research the technique used in implant placement in the delayed immediate implant placement was the flapless technique, Gapski et al. in 2003 (35), mentioned that flapless implant placement offers many advantages; such as, simplifying the procedure, less time consuming, slight or no postoperative pain, discomfort and odema, faster soft tissue healing around the implant, reducing possibility of contamination and infection and gaining excellent final esthetics.

This is in agreement with, Hahn in 1999 (36) who reported that avoiding creation of flap results in less postoperative pain and discomfort. In addition, leaving the periosteum intact on buccal and lingual aspects of the ridge maintains a better blood supply to the site reducing the likelihood of resorption.

On the other hand, Campelo and Camarain 2002 (37), mentioned some disadvantages of flapless surgery, such as it prevents direct visualisation of bony configuration during drilling. Since flapless implant placement is a blind surgery, working blindly may lead to incorrect implant placement or perforation of the buccal plate of bone.

After comparing the results of both groups it was shown that the primary stability of delayed immediate placed implants was greater than the primary stability of immediate placed implants which resulted in a t-value (student t-test) of 0.792 and the p- value of the study was 0.458 which was statistically insignificant.

These findings are in agreement with Kim et al. (38) in 2015 who stated that although the mean ISQ of immediately placed implants is lower than implants placed in healed sites, all ISQ values were raised to a clinically successful value throughout the osseointegration process before implant loading. So it seems that there are no significant differences between primary stability of implants placed immediately with those placed in healed sites whether partially healed sites (filled with soft tissue only as in delayed immediate sites) or fully healed sites (filled with soft tissue and bone).

Also Rowan et al. (39), in 2015 emphasized these finding and results stating that as there were no implant failures in the follow up period, results of this study support 
the concept of immediate implant placement following tooth extraction under favorable conditions with delayed implant loading.

Also Kunnekel et al. in 2011 (40), stated that there is no significant difference between the primary stability of the implants placed immediately with those placed in healed sites whether partially healed sites (filled with soft tissue only as in delayed immediate sites) or fully healed sites (filled with soft tissue and bone).

\section{CONCLUSION}

The primary stability of delayed immediate placed implants is greater than primary stability of immediate placed implants but it's statistically insignificant. Future studies including more patients and longer follow up are needed to assess the long-term success of immediately placed implants.

\section{CONFLICT OF INTEREST}

The authors declare that they have no conflicts of interest.

\section{REFERENCES}

1. Misch CE. Contemporary implant dentistry. 2nded. St Louis: Mosby, Inc, 1999. 551-4.

2. Brånemark PI, Adell R, Breine U, Hansson BO, Lindström J, Ohlsson A. Intra-osseous anchorage of dental prostheses. I. Experimental studies. Scand J Plast Reconstr Surg. 1969; 3: 81-100. Quoted from: O’Sullivan D, Sennerby L, Meredith N. Measurements comparing the initial stability of five designs of dental implants: a human cadaver study. Clin Implant Dent Relat Res. 2000; 2 (2): 85-92.

3. Schroeder A, Pohler O, Sutter F. Tissue reaction to an implant of a titanium hollow cylinder with a titanium surface spray layer. SSO Schweiz Monatsschr Zahnheilkd. 1976; 86: 713-27.

4. Brånemark PI, Svensson B, van Steenberghe D. Ten-year survival rates of fixed prostheses on four or six implants ad modum Brånemark in full edentulism. Clin Oral Implants Res. 1995; 6: 173-9.

5. Hämmerle $\mathrm{CH}$, Chen ST, Wilson TG Jr. Consensus statements and recommended clinical procedures regarding the placement of implants in extraction sockets. Int J Oral Maxillofac Implants. 2004;19:26-8.

6. Chen ST, Buser D. Clinical and esthetic outcomes of implants placed in post-extraction sites. Int $\mathrm{J}$ Oral Maxillofac Implants. 2009; 24: 186-217.

7. Schropp L, Isidor F. Timing of implant placement relative to tooth extraction. J Oral Rehabil. 2008; 35:33-43.

8. Atsumi M, Park SH, Wang HL. Methods used to assess implant stability: Current status. Int J Oral Maxillofac Implants. 2007; 22: 743-54.

9. Albrektsson T, Zarb GA. Current interpretations of the osseointegrated response: clinical significance. Int $\mathrm{J}$ Prosthodont. 1993; 6: 95-105.

10. Becker W, Sennerby L, Bedrossian E, Becker BE, Lucchini JP. Implant stability measurements for implants placed at the time of extraction: a cohort, prospective clinical trial. J Periodontol. 2005; 76: 391-7.

11. Huwiler MA, Pjetursson BE, Bosshardt DD, Salvi GE, Lang NP. Resonance frequency analysis in relation to jawbone characteristics and during early healing of implant installation. Clin Oral Implant Res. 2007; 18: 275-80.
12. Meredith N, Alleyne D, Cawley P. Quantitative determination of the stability of the implant-tissue interface using resonance frequency analysis. Clin Oral Implants Res. 1996; 7: 261-7.

13. Rompen E, DaSilva D, Lundgren AK, Gottlow J, Sennerby L. Stability measurements of a double-threaded titaniumimplant design with turned or oxidised surface. Appl Osseointegration Res. 2000; 1: 18-20.

14. Bornstein M, Hart CN, Halbritter SA, Morton D, Buser D. Early Loading of Non -submerged Titanium Implants with a Chemically Modified Sand-Blasted and Acid- Etched Surface: six-Month Results of a Prospective Case Series Study in the Posterior Mandible Focusing on Peri-Implant Crestal Bone Changes and Implant Stability Quotient (ISQ) Values. Clin Implant Dent Relat Res. 2009;11:338-47

15. Degidi M, Daprile G, Piattelli A. Determination of primary stability: a comparison of the surgeon's perception and objective measurements. Int J Oral Maxillofac Implants. 2010; 25: 558-61.

16. Jimenez D, Shah K, El-Ghareeb M, Aghaloo T, Pi-Anfruns $\mathrm{J}$, Hameed S, et al. Use of Osstell for determination of implant staging and loading protocols to improve implant success rates. Poster at AO Academy of Osseointegration Annual Meeting. 2009.

17. Peev S. Application of Platelet-Rich Plasma as an Accelerator of the Secondary Stability of ImmediateLoaded implants. Inside Dent. 2007; 13: 8-13.

18. Sennerby L, Meredith N. Implant stability measurements using resonance frequency analysis: biological and biomechanical aspects and clinical implications. Periodontology 2000. 2008; 47: 51-66.

19. Boonstra AM, SchiphorstPreuper HR, Reneman MF, Posthumus JB, Stewart RE. Reliability and validity of the visual analogue scale for disability in patients with chronic musculoskeletal pain. Int J Rehabil Res 2008; 31: 165-9.

20. McClanahan SF, Bartizek RD, Biesbrock AR. Identification and consequences of distinct Löe-Silness gingival index examiner styles for the clinical assessment of gingivitis. $\mathrm{J}$ Periodontol 2001; 72: 383-92.

21. Steflik D, Koth DL, Robinson F, McKinney R, Davis B, Morris C, et al. Prospective investigation of the singlecrystal sapphire endosteal dental implant in humans: Tenyear results. J Oral Implantol 1995; 21: 8-18.

22. El Askary A. Presurgical consideration: A Reconstructive Aesthetic Implant Surgery. 1sted. Ch .2. USA: WileyBlackwell Publishing Company, 2003.p.35.

23. Adell R. Tissue integrated prostheses in clinical dentistry. Int Dent J. 1985; 35(4): 259-65.

24. Denissen HW, Kalk W. Preventive implantations. Int Dent J. 1991; 41:17-24.

25. Bornstein MM, Cionca N, Mombelli A. Systemic conditions and treatments as risks for implant therapy. Int $\mathrm{J}$ Oral Maxillofac Implants. 2009; 24: 12-27.

26. Gómez-de Diego R, Mang-de la Rosa Mdel R, RomeroPérez MJ, Cutando-Soriano A, López-Valverde-Centeno A. Indications and contraindications of dental implants in medically compromised patients: Med Oral Patol Oral Cir Bucal. 2014; 19: e483-9.

27. Duyck J, Naert I. Failure of oral implants: aetiology, symptomsand influencing factors. Clin Oral Investig.1998; 2: $102-14$.

28. Tadi DP, Pinisetti S, Gujjalapudi M, Kakaraparthi S, Kolasani B, Vadapalli SH. Evaluation of initial stability and crestal bone loss in immediate implant placement: An in 
vivo study. J Int Soc Prev Community Dent. 2014; 4: 13944.

29. Sim CP, Lang NP. Factors influencing resonance frequency analysis assessed by Osstell mentor during implant tissue integration: I. Instrument positioning, bone structure, implant length. Clin Oral Implants Res. 2010; 21: 598-604.

30. Kessler-Liechti G, Zix J, Mericske-Stern R. Stability measurements of 1-stage implants in the edentulous mandible by means of resonance frequency analysis. Int $\mathrm{J}$ Oral Maxillofac Implants. 2008; 23: 353-8.

31. Davies JE. Mechanisms of endosseous integration. Int J Prosthodont. 1998; 11: 391-401.

32. Jaramillo R, Santos R, Lázaro P, Romero M, Rios-Santos JV, Bullón P, et al. Comparative analysis of 2 resonance frequency measurement devices: Osstell Mentor and Osstell ISQ. J Implant Dent. 2014; 23: 351-6.

33. Strbac GD, Unger E, Donner R, Bijak M, Watzek G, Zechner $\mathrm{W}$. Thermal effects of a combined irrigation method during implant site drilling. A standardized in vitro study using a bovine rib model. Clin Oral Implants Res. 2014; 25: 665-74.

34. Garber DA, Salama MA, Salama H. Immediate total tooth replacement. Compend Contin Educ Dent 2001; 22: 210-8.

35. Gapski R,Wang HL, Mascarenhas P, Lang NP. Critical view of immediate implant loading. Clin Oral Implants Res. 2003; 14: 515-27.

36. Hahn J. Clinical uses of osteotome. J Oral Implantol 1999; 25 (1) :23-9.

37. Campelo LD, Camara JRD. Flapless implant surgery: 10year clinical retrospective analysis. Int J Oral Maxillofac Implants. 2002; 17: 271-6.

38. Kim SL, Ribeiro ALVL, Atlas AM, Saleh N, Royal J, Radvar $\mathrm{M}$, et al. Resonance frequency analysis as a predictor of early implant failure in the partially edentulous posterior maxilla following immediate non- functional loading or delayed loading with a single unit restorations. Clin Oral Implants Res. 2015; 26:183-90.

39. Rowan M, Lee D, Pi-Anfruns J, Shiffler P, Aghaloo T, Moy PK. Mechanical versus biological stability of immediate and delayed implant placement using resonance frequency analysis . J Oral Maxillofac Surg. 2015; 73: 253-7.

40. Kunnekel AT, Dudani MT, Nair CK, Naidu EM, Sivagami G. Comparison of Delayed implant placement versus Immediate implant placement using resonance frequency analysis: A pilot study in rabbits. J Oral Implantol.2011; 37 : 543-7. 